\title{
MIGRAÇÃO INTERNACIONAL, ECONOMIA URBANA E TERRITORIALIDADES
}

\author{
INTERNATIONAL MIGRATION, URBAN ECONOMY AND TERRITORIALS
}

MIGRATIONS INTERNATIONALES, ÉCONOMIE URBAINE ET TERRITORIAUX

\author{
Denise Cristina Bomtempo - Universidade Estadual do Ceará - Fortaleza - Ceará - Brasil \\ rdenise.bomtempo@uece.br
}

\section{Resumo}

Neste início do século XXI, o Ceará se insere no novo quadro da migração no Brasil, entre outros aspectos, por receber importante contingente de migrantes internacionais, com destaque para os africanos, chineses e sul-coreanos. Como recebeu investimentos que alteraram a sua dinâmica territorial e econômica, Fortaleza se apresentou como uma metrópole que reuniu serviços e investimentos, por consequência da oferta de empregos. Assim, o objetivo deste texto é entender a recente migração internacional pela via da economia urbana e das múltiplas territorialidades produzidas pelos migrantes, principalmente para a capital do Ceará, mas também para cidades com centralidade na rede urbana. Desse modo, afirmamos que a presença dos migrantes internacionais neste estado, permite, por um lado, o surgimento de uma economia urbana da migração e novas territorialidades - sentidas pelos fluxos vinculados ao trabalho, estudo, moradia, consumo e lazer. Por outro lado, é possível compreender o perfil dos sujeitos migrantes, suas trajetórias construídas e conflitos existentes a partir das práticas cotidianas. Em síntese, a migração internacional materializada na escala das cidades em apreço é um exemplo da inserção do Ceará de maneira diferenciada na divisão territorial do trabalho do século XXI.

Palavras-chave: Migração. Economia urbana. Territorialidade. Ceará.

\section{Abstract}

At the beginning of the 21st century, Ceara is inserted in the new migration scenario in Brazil due to, among other aspects, the receiving of a significant number of international migrants, especially Africans, Chinese and South Koreans. Fortaleza received investments that changed its territorial and economic dynamics presenting itself as a metropolis able to gather services and investments, and consequently, job offers. This way, this text aims to understand the recent international migration through the urban economy and the multiple territorialities produced by migrants, mainly those that move to the capital city of Ceara, and also to other cities with a centrality role in the urban network. Thus, we affirm that the presence of international migrants Ceara state allows the emergence of an urban economy of migration and new territorialities - perceived by the flows linked to work, study, housing, consumption and leisure. On the other hand, it is also possible to understand the profile of the migrant subjects as well as their constructed trajectories and existing conflicts through the daily practices. In summary, the international migration materialized in the scale of the cities in question is an example of the Ceara insertion in a differentiated way in the territorial division of labor of the 21st century.

Keywords: Migration. Urban economy, Territoriality. Ceara.

\section{Résumé}

Dans ce début du XXle siècle, l'état du Ceará fait partie du nouveau scénario de migration au Brésil, parmi d'autres aspects, à cause d'accueillir un nombre important de migrants internationaux, notamment africains, chinois et sud-coréens.Comme a reçu des investissements qui ont modifié sa dynamique territoriale et économique, Fortaleza s'est présentée comme une métropole qui a rassembler services et investissements, par 
conséquent, offres d'emploi. Ainsi, l'objectif de ce texte est de comprendre la récente migration internationale au moyen de l'économie urbaine et les multiples territorialités produites par les migrants, principalement pour la capitale du Ceará, mais également pour les villes ayant une centralité dans le réseau urbain. De cette façon, nous affirmons que la présence de migrants internationaux dans cet état permet, d'une part, l'émergence d'une économie urbaine migratoire et de nouvelles territorialités - ressentie par les flux liés au travail, aux études, au logement, à la consommation et aux loisirs. D'autre part, il est possible de comprendre le profil des sujets migrants, leurs trajectoires construites et des conflits existants a partir des pratiques quotidiennes. En résumé, la migration internationale matérialisée dans l'échelle des villes en question est un exemple de I'insertion du Ceará de façon différenciée dans la division territoriale du travail du XXle siècle.

Mots-clés: Migration. Économie urbaine. Territorialité. Ceará.

Introdução

Os estudos de mobilidades e migrações são inerentes à própria estruturação das ciências que têm enquanto objeto de estudo a sociedade, com destaque para a Geografia, pois entre as dimensões da análise referente à sociedade-natureza, encontra-se, de acordo com Max Sorre $(1955,1991)$, aquela vinculada ao espaço habitado, entendido enquanto expressão maior do "gênero de vida", estudado por Paul Vidal de la Blache, geógrafo francês do século XIX. Desse modo, de acordo com Bomtempo (2003), as mobilidades e as migrações permitem compreender as dinâmicas de circulação, distribuição e formações territoriais ao longo do tempo em várias escalas, sejam elas regionais, nacional ou global.

Neste texto, nossa preocupação central é compreender a relação entre as dinâmicas econômicas, políticas e territoriais que impulsionam fluxos migratórios, com enfoque para as recentes migrações do século XXI que se entrelaçam na escala da cidade e são responsáveis pelo surgimento de uma economia urbana da migração, bem como de territorialidades vinculadas ao trabalho, à moradia, ao consumo e ao lazer.

Assim, para fazer a leitura do objeto, o recorte temporal está centrado no período da globalização, na qual afeta os territórios de maneira distinta desde a década de 1970, dado: a) o desenvolvimento desigual e combinado do capitalismo, que se materializa nos lugares de maneira desigual e combinada; b) a formação socioespacial na escala do país, com destaque para ação dos agentes (com atuação nacional e local); c) os sujeitos envolvidos nos fluxos migratórios recentes.

Enquanto recorte empírico, nossa leitura está na cidade de Fortaleza e alguns municípios da sua Região Metropolitana e fomentam uma economia urbana e múltiplas territorialidades que estão visíveis e são 
sentidas nas práticas cotidianas dos (não) migrantes, com destaque para a migração africana, chinesa e sul-coreana.

Dinâmica territorial e migração internacional: caminhos para leitura da economia urbana e da territorialidade na cidade

No período atual, a articulação entre dinâmicas territoriais, mobilidade e migração internacional é um caminho que pode ser trilhado na tentativa de compreender as novas configurações que se materializam no território brasileiro neste início do século XXI.

A mobilidade no período atual, de acordo com Haesbaert (2004) e Augé (2010), revela movimentos de população que coexistem em múltiplas escalas. No contexto de "aceleração contemporânea", as mobilidades e sobretudo as migrações, só se configuram enquanto um fenômeno veloz, dada a comunicação instantânea, a circulação de produtos, de imagens e de informações.

Para Haesbaert (2004), a mobilidade é o meio e não o fim da migração. É uma espécie de intermediação de uma vida em busca de certa estabilidade. As migrações, no período atual são impulsionadas por questões políticas, culturais, ambientais e econômicas. Sendo que os fatores econômicos estão vinculados à estrutura desigual e combinada do sistema capitalista e por isso interfere, entre outros, no movimento de população realizado de acordo com os interesses estruturais e conjunturais desse sistema.

Consoante à Goettert (2010), as migrações na escala internacional só passaram a ocorrer mediante a existência do Estado-Nação. Ainda de acordo com o autor, não é a migração que explica o mercado internacional do trabalho, mas é o mercado internacional do trabalho que explica a migração de trabalhadores. Desse modo, a migração é sempre uma mudança, e na migração muda quem migra, quem fica e mudam também os lugares.

Do ponto de vista econômico, associado à dinâmica do mercado tornado global, a migração pode ser impulsionada pela perspectiva de conquista dos sonhos - entendida como melhoria de condições de vida relacionada ao emprego, à moradia, ao consumo e ao lazer, que não está sendo possível de conquistar no lugar de origem (Bomtempo, 2003, 2009, 2010). A migração, portanto, é encarada enquanto possibilidade de buscar 
uma remuneração mais ampliada, mesmo que em algumas ocasiões não seja sinônimo de boas condições de trabalho. Por outro lado, a migração pode ser impulsionada pela tentativa de usufruir melhores ganhos pela diferença do poder aquisitivo da moeda de um país para outro, no caso da migração internacional.

De maneira mais recente, de acordo com Haesbaert (2004), temos as migrações de profissionais e empresários que realizam inúmeros fluxos na perspectiva de investir capital ou expandir seus negócios. Cada um dos motivos compreendidos implica em diferentes níveis de territorialização, relacionadas ao controle que o migrante tem do seu território (de migração e origem).

Assim, é possível afirmar que os níveis de territorialização se diferenciam de acordo com a classe social em que está inserido o migrante. Considerar tal aspecto, no período atual, é compreender que temos diferentes tipos de movimentos migratórios, ou seja, de profissionais qualificados, de empresários, e não apenas de força de trabalho industrial, como afirmou Gaudemar (1977). Essas diversas migrações geram diferentes níveis de territorialização e territorialidades visíveis na paisagem das cidades.

Desse modo, a migração enquanto um fenômeno (Sorre, 1951) e um "fato social completo" (Sayad, 1998), necessita de uma leitura interdisciplinar. Ainda, para compreendê-las, no período atual, é preciso considerar a estrutura, a conjuntura, os processos, os agentes e os sujeitos migrantes que se articulam de maneira inter- e multiescalar. É próprio da Geografia, compreender as dinâmicas do território e da população pela via da migração e do migrante. Consoante a Sayad (1998, p. 16), “[...] o imigrante só existe na sociedade que assim o denomina a partir do momento em que atravessa suas fronteiras e pisa seu território".

O migrante é uma categoria complexa, pois remete a vários tipos de indivíduos e grupos sociais envolvidos no processo migratório. De acordo com Sayad (1998, p. 54), “[...] o migrante é sobretudo uma força de trabalho provisória, temporária, em trânsito. Foi o trabalho que fez surgir o migrante, é ele, quando termina, que decreta sua negação e o empurra a não ser."

Diante do que está sendo apresentado, compreendemos que existe um desafio teórico-metodológico no trabalho referente à temática migratória, já que diante das novas configurações econômicas e espaciais 
deste início do século XXI, entende-se que há a necessidade de se formular caminhos para a construção de uma nova Geografia da migração. Para tanto, além de considerar a estrutura, a conjuntura, os processos, os agentes e os próprios migrantes de maneira inter- e multiescalar, é preciso estar ciente de que existem fluxos simultâneos que coexistem espacialmente e com isso tem-se uma nova configuração da migração a partir das causas, direções, conteúdo, razões, trajetórias de vida e trabalho, redes, atividades econômicas desenvolvidas pelos migrantes e territorialidades.

Os recentes fluxos migratórios internacionais que entrelaçam o Brasil: a região Nordeste e o Ceará

No que se refere ao Brasil, as migrações internacionais e internas aparecem como partes integrantes do processo de formação socioespacial do país. No período atual, no contexto da globalização, o direcionamento dos fluxos migratórios internacionais (Cartograma 1) e internos que se materializam e se entrelaçam no território brasileiro é diferente de outros períodos, sobretudo devido à dispersão das atividades econômicas vinculadas à indústria, ao comércio, aos serviços e ao agronegócio.

A partir do Cartograma 1, constata-se que neste início do século XXI, o Brasil, na América Latina, assume um papel de liderança no que concerne à recepção de migrantes, já que a migração de fronteira se apresenta com notoriedade a partir dos referidos países: Paraguai, Peru, Bolívia, Argentina, Guiana Francesa. Por sua vez, evidencia-se também a intensa migração dos haitianos para o Brasil que ocorreu de maneira maciça no início de 2010 até 2014. Ainda em relação ao continente americano, a migração de sujeitos provenientes dos Estados Unidos é igualmente significativa. A migração europeia (Portugal, Itália, Espanha, França) aparece com proeminência. Vindos da Ásia, destacam-se chineses e coreanos do sul. 
Cartograma 1 - Procedência dos estrangeiros com registro no Brasil (2000- 2004)

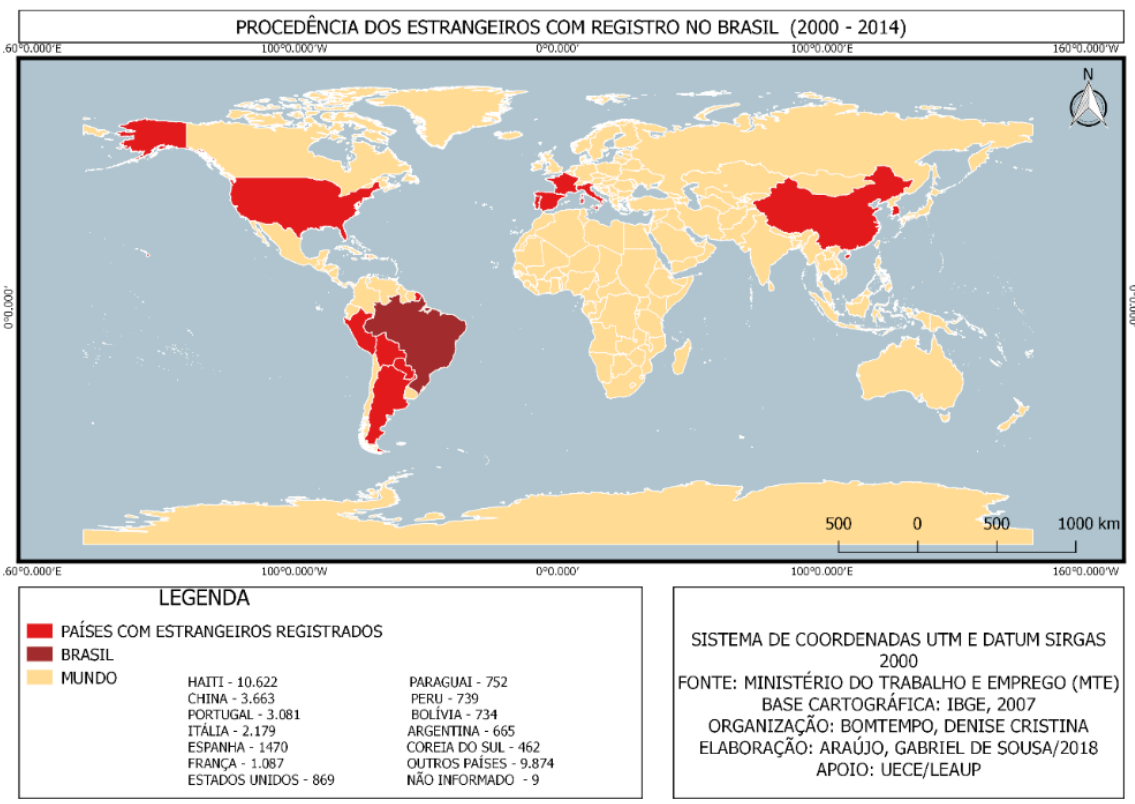

Fonte: MTE (2018); IBGE (2007).

No Brasil, além de São Paulo, os estados da região Nordeste, em especial Bahia e Ceará (Cartograma 2), que durante décadas foram emissores de migrantes, atualmente se transformam em potenciais receptores, e alcançam notoriedade por intermédio das migrações internas e internacionais.

No Ceará, de maneira especial, na metrópole - Fortaleza, bem como nas cidades médias e pequenas é possível identificar a existência da migração interna: ou seja, a movimentação de sujeitos dentro do próprio país, oriundos de estados da própria região Nordeste, como também sujeitos advindos de outras regiões brasileiras, configurando assim a migração inter-regional. Mas, o que se evidencia é a presença da migração internacional, já que são várias as nacionalidades presentes na paisagem cotidiana das cidades nordestinas e cearense. Como integrantes dessa migração se se fazem presentes os sujeitos europeus, latino-americanos, chineses, coreanos e africanos, grupos que se inserem, a partir das redes migratórias, em diversas atividades laborais (enquanto estudantes, investidores e trabalhadores com ou sem qualificação profissional) e 
como consequência, dinamizam a economia urbana e fomentam novas territorialidades na escala da cidade e da região.

Cartograma 2 - Procedência dos estrangeiros com registro no Brasil (2000-2004)

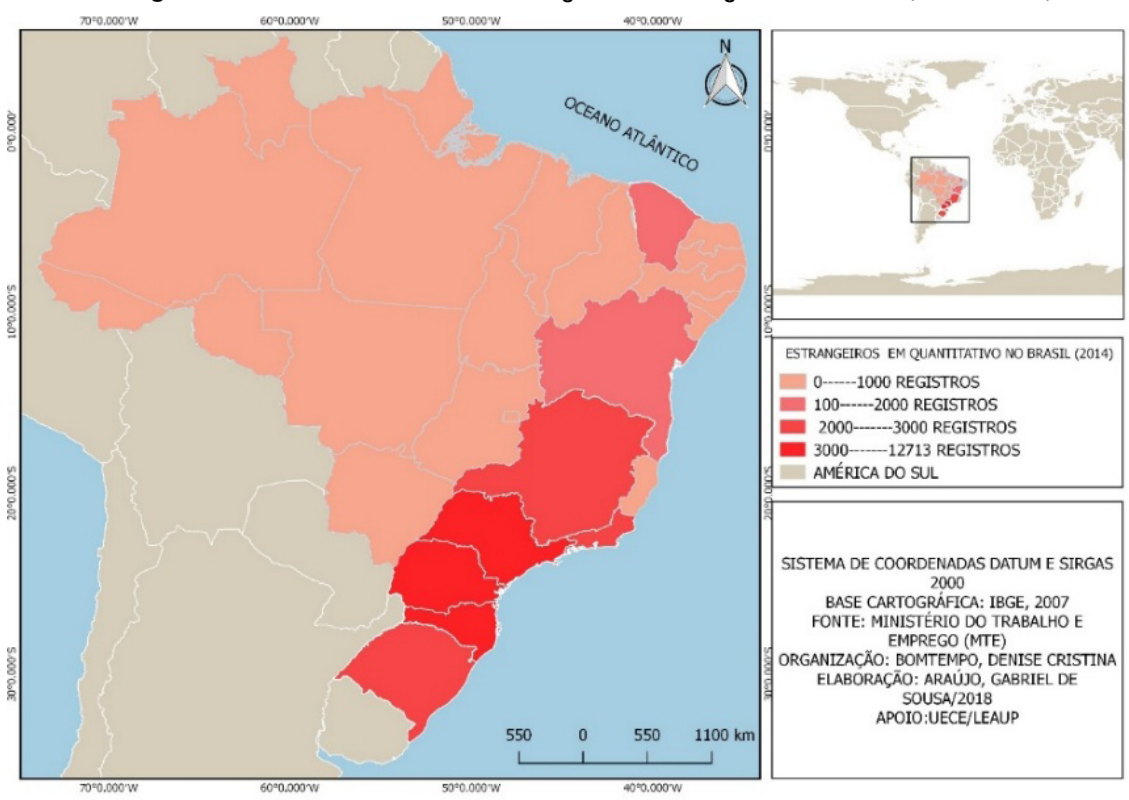

Fonte: MTE (2018); Bomtempo; Araújo (2018).

Diante do apresentado, este artigo tem como objetivo compreender as territorialidades da migração internacional no estado do Ceará, com foco para a cidade de Fortaleza e alguns municípios da sua Região Metropolitana, no período de 2000 até os dias atuais, do ponto de vista das práticas cotidianas vinculadas à moradia, ao trabalho, ao consumo e ao lazer dos migrantes internacionais residentes no recorte empírico em apreço.

De acordo com a Junta Comercial do Estado do Ceará (JUCEC, 2014), existem no estado uma média de 4.500 investidores estrangeiros de 57 nacionalidades. Dos investimentos realizados pelos migrantes estrangeiros sobressaem: a) grandes investimentos: indústria; agronegócio; compra de terras; incorporação; construção civil; imobiliária; hotelaria; importação 
e exportação; e b) pequenos e médios investimentos na economia urbana: comércio e serviços.

Os investimentos são feitos sobretudo em Fortaleza, em municípios do litoral e do interior do estado, com papéis de centralidade na rede urbana cearense (Cartograma 3). Entre os migrantes investidores, o realce fica a cargo dos europeus, aos latino-americanos, africanos, chineses e coreanos. Os coreanos representam um dos grupos mais recentes que chegou ao Ceará, mas que mostra forte dinamismo, tanto do ponto de vista dos investimentos, como também na quantidade de sujeitos envolvidos no fluxo migratório.

De maneira massiva, os coreanos chegaram somente no ano de 2010, em consoante à chegada dos investimentos da Companhia Siderúrgica do Pecém (CSP), localizada no Complexo Industrial e Portuário do Pecém, em São Gonçalo do Amarante. Enquanto migrantes investidores, destacam-se também os chineses. Como afirmam Ferreira e Bomtempo (2018), trata-se de um grupo de migrantes que dinamizou o circuito superior, superior marginal e inferior da economia urbana das cidades cearenses. Os europeus e latino-americanos, que chegam ao Ceará desde o início do século XXI, são os responsáveis pelos investimentos realizados em atividades do agronegócio, industriais, comerciais e de serviços, bem como aquisição de terras, sobretudo no litoral cearense.

Ainda em relação à migração internacional, apresenta importância os africanos que são investidores, trabalhadores qualificados e que não dispõem de qualificação formal, entretanto, sobressaem os africanos que migram na perspectiva de estudar, por meio de convênios com universidades públicas e privadas instaladas no território cearense. De acordo com Bomtempo e Sena (2018), no período de 2000-2017 os estudantes africanos que vieram para estudar no Brasil são originários respectivamente dos seguintes países: Cabo-Verde, Guiné-Bissau, Angola, República Democrática do Congo, São-Tomé e Príncipe e Benin. 
Cartograma 3 - Migração e investimentos estrangeiros no Ceará, 2014
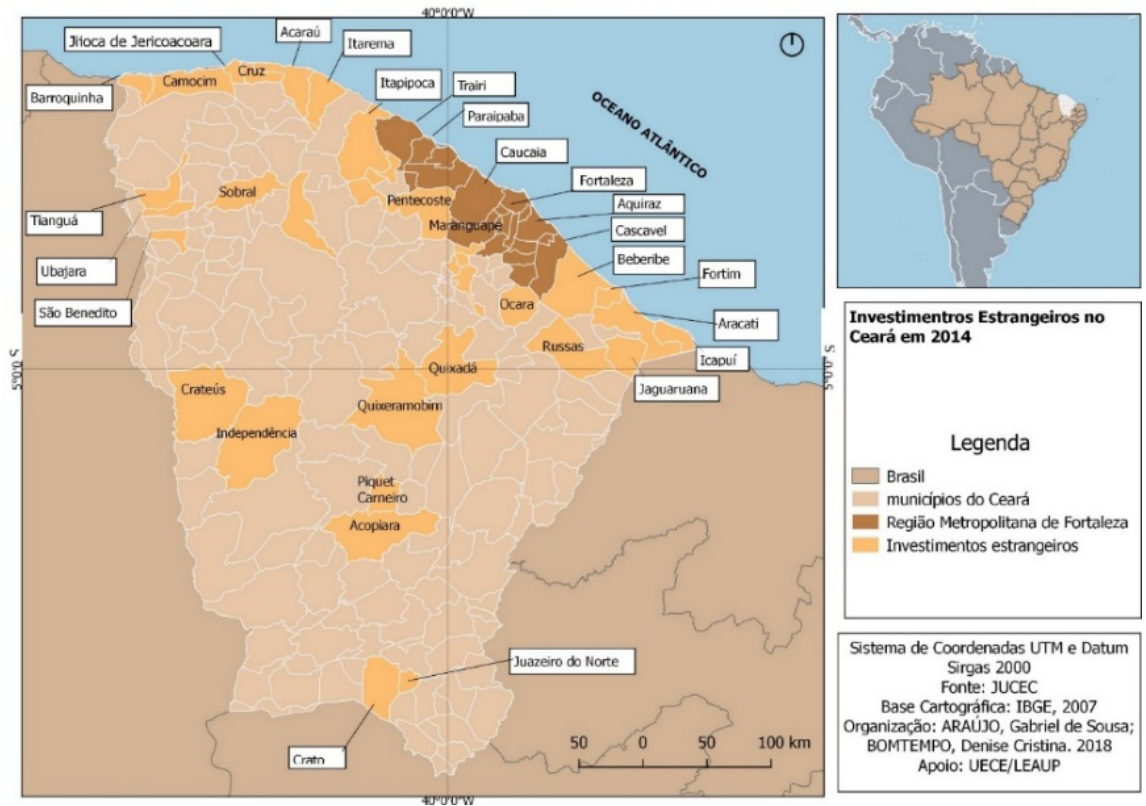

Sistema de Coordenadas UTM e Datum Sirgas 2000 Fonte: JUCEC Base Cartográfica: IBGE, 2007 Organizaçăo: ARAỦJO, Gabriel de Sousa; BOMTEMPO, Denise Cristina. 2018

Fonte: JUCEC (2014). Bomtempo; Araújo (2018).

Os migrantes estrangeiros ao permanecerem em território cearense, não estão sozinhos, mas organizados em redes migratórias na qual articulam pessoas e lugares na perspectiva de construir suas territorialidades múltiplas no território de migração. De acordo com Raffestin (1993, p. 160-162), a territorialidade pode ser definida como um

[...] conjunto de relações que se originam num sistema tridimensional sociedade-espaço-tempo. [...] A territorialidade se manifesta em todas as escalas espaciais e sociais; ela é consubstancial a todas as relações e seria possível dizer que, de certa forma, é a "face vivida" da "face agida" do poder.

Ainda em relação às redes na migração, Marandolla Júnior e Del Gallo (2010), afirmam que a construção de redes é um fator importante para que o migrante consiga, num primeiro momento, permanecer no lugar de migração e tecer a sua relação consigo, com o outro e com o lugar.

Ao se inserir em cidades do Ceará, os sujeitos migrantes estrangeiros estruturam suas próprias redes - formadas majoritariamente por sujeitos 
que possuem a mesma origem territorial -, dedicam-se às atividades laborais como trabalhadores qualificados e não qualificados, realizam investimentos - fazendo surgir uma economia urbana oriunda de capital migrante -, e realizam múltiplas territorialidades a partir da escolha do local de moradia, trabalho, consumo e lazer. Desse modo, é possível que seja compreendido empiricamente a configuração de um uso diferenciado do espaço e do território na cidade, além da coexistência de diversas territorialidades materializadas a partir de multiescalaridades.

No conjunto dos migrantes estrangeiros existentes no Ceará, para compreender a configuração da economia urbana da migração e as territorialidades, tomaremos como exemplo a migração dos africanos, chineses e coreanos, por serem grupos que aparecem de maneira mais recente nas cidades cearenses, em comparação com os latino-americanos, estadunidenses e europeus.

Migração internacional, economia urbana e territorialidade: os africanos no Ceará estudantes, trabalhadores e investidores

Em fins do século XX e início do século XXI, a migração de africanos para o Ceará ocorreu para fins de trabalho (qualificado e não qualificado - do ponto de vista formal) e principalmente para o estudo em nível superior. De acordo com Langa (2012), no Ceará, a migração de africanos para fins para inserção no ensino superior teve início na segunda metade da década de 1990, com o primeiro grupo oriundo de Angola. Nesse período, vinham somente estudantes de países africanos que falavam a língua portuguesa para se integrar na Universidade Federal do Ceará (UFC), através do Programa de Estudantes-Convênio de Graduação (PEC-G²). A partir de 1998, iniciou-se a migração de estudantes bissauguineenses e cabo-verdianos e, dois anos depois, estudantes são-tomenses, angolanos e moçambicanos. Em 2001, por sua vez, iniciou-se o processo de migração de jovens saídos daquele continente para realização de estudos em faculdades e universidades privadas de Fortaleza e com isso houve um maior volume de pessoas, diversidade do perfil, criação de redes migratórias e territorialidades africanas presente nas cidades cearenses.

No Ceará, a presença dos estudantes africanos permite a construção de territorialidades. A partir da pesquisa empírica (fev./ago. 2018), notou-se na cidade de Fortaleza as múltiplas territorialidades dos estudantes 
africanos no Ceará por meio da moradia, trabalho e estudo, conforme demonstra o cartograma abaixo.

Cartograma 4 - Africanos em Fortaleza: trabalho, residência e estudo

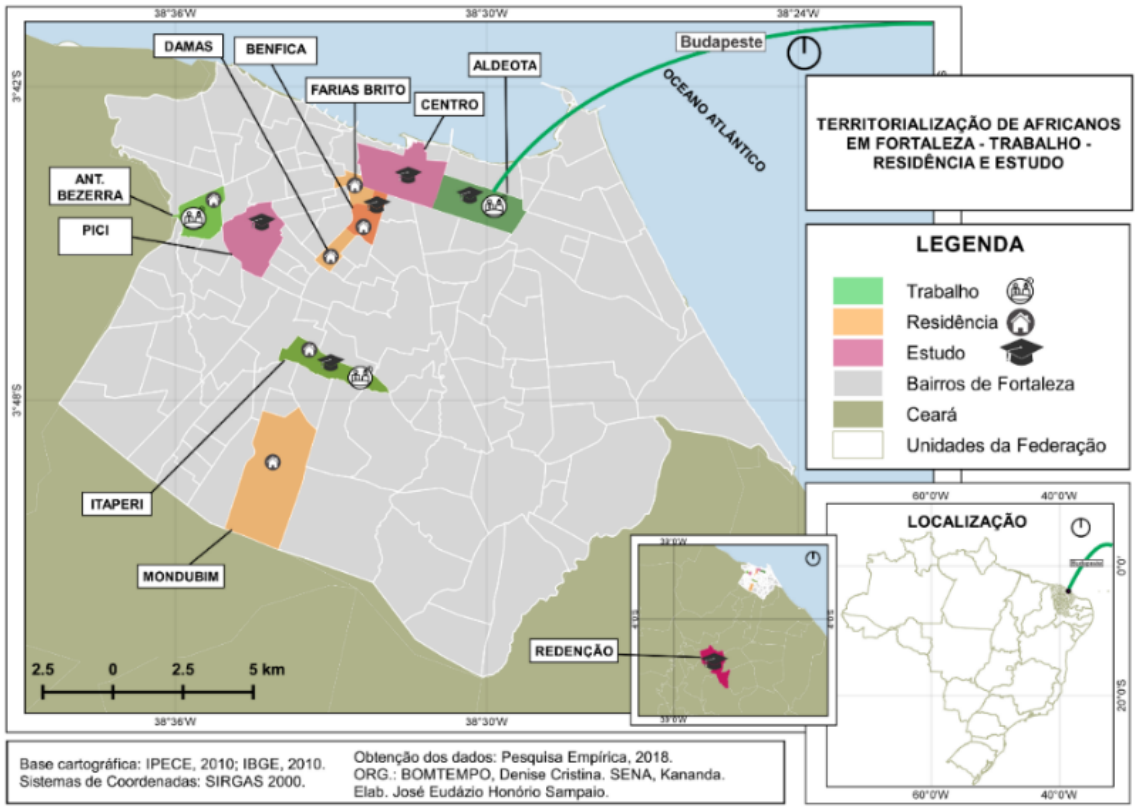

Fonte: Pesquisa Empírica (2018); Bomtempo; Sena; Sampaio (2018).

Num primeiro momento, a escolha do local de moradia (a exemplo dos bairros Benfica, Damas e Farias Brito) se define pela proximidade com a instituição de ensino (Centro e Pici) em que estão vinculados, como também a existência de pessoas provenientes da mesma origem territorial, dada a possibilidade de amortecer os impactos de estranhamento nos primeiros meses de chegada ao Brasil. Posteriormente, devido por um lado, à ampliação do conhecimento empírico da cidade, como também pelo custo de vida, uma parte significativa dos entrevistados escolhem residir em bairros mais periféricos da cidade de Fortaleza, a exemplo do Mondubim.

A territorialidade dos estudantes africanos em Fortaleza se faz também pelo trabalho. A partir desta variável, a territorialidade é 
múltipla, já que: a) existem sujeitos que trabalham nos bairros com maior concentração de atividades comerciais e de serviços: Centro, Aldeota e Meirelles - predominam aqueles que chegaram no Brasil enquanto estudantes, e que atualmente já possuem qualificação profissional, passaram a residir no Brasil e estão inseridos em atividades vinculadas ao "circuito superior da economia urbana" e no mercado de trabalho formal; b) existem sujeitos que desenvolvem atividades vinculadas ao "circuito inferior da economia urbana", realizam trabalhos esporádicos e mormente precários em bairros nos quais a concentração de atividades turísticas é uma realidade, a exemplo da "Beira Mar” e algumas áreas do centro da cidade de Fortaleza. Nesta modalidade, para ampliar a renda mensal, encontramos estudantes africanos que trabalham em diversas atividades vinculadas ao comércio e serviços. c) existe também um grupo de estudantes - profissionais que desenvolvem suas atividades laborais são “donos do próprio negócio” no local de residência ou próximo (lojas de confecções com tecidos africanos - capulanas; empresa de instalação de redes de internet; bares e restaurantes que além de ser um território de trabalho - controlado pelo estudante - profissional, é um espaço em que a territorialidade capitaneada pelo lazer.

A territorialidade dos estudantes africanos no Ceará é sentida também pelos espaços de discussão política que foram organizados por esses sujeitos. $\mathrm{O}$ realce pode ser dado às associações estudantis. Elas buscam defender os direitos de estudantes africanos (que passam por situações múltiplas de constrangimentos) e promover a integração entre eles e também com a sociedade cearense.

Ainda em relação às territorialidades por meio das práticas cotidianas vinculadas ao lazer, é possível mencionar o esporte, principalmente o futebol, além de encontros nos shopping centers da cidade de Fortaleza e as festas africanas, que representam momentos de confraternização para rever amigos e conhecidos, diminuem as saudades da terra de origem por intermédio das músicas, danças e comidas, e contribuem para a união do grupo e resolução de conflitos.

As territorialidades dos estudantes africanos no Ceará do início até os dias atuais, tornou-se múltipla, já que existem: a) estudantes que chegam constantemente pelos projetos de cooperação internacional de estudo; b) estudantes que ao findar a graduação não retornam, mas fixam 
residência e ampliam seus espaços de participação e práticas cotidianas na cidade pela via do trabalho; c) estudantes que se inserem em atividades laborais temporárias para ampliar o rendimento mensal e assim suprir as demandas de consumo. Em síntese, a presença dos estudantes africanos no Ceará, sobretudo na cidade de Fortaleza, permitiu compreender a emergência de conflitos entre os sujeitos e os lugares envolvidos na migração, a configuração de novas paisagens e as territorialidades que são criadas a partir desse grupo migrante - pela moradia, trabalho, consumo e lazer.

Vale ressaltar que a recente migração africana no Ceará não é formada apenas por estudantes que realizaram mobilidade para fins de estudo, mas existe um perfil mais diverso, a saber: a) migrantes africanos com qualificação profissional que adentram o território cearense e se inserem em atividades com formação profissional; b) migrantes ilegais que realizam trabalhos precários e mal remunerados; c) migrantes investidores, que aparecem numa situação crescente nos últimos 12 anos, conforme pode ser constatado no Cartograma 5, a respeito dos investimentos africanos em território cearense no período de 2000 a 2012.

Notamos, a partir do Cartograma 5, que a metrópole Fortaleza concentra um número maior de investimentos africanos no território cearense; seguidos pelos municípios de Beberibe e Aquiraz, localizados na Região Metropolitana de Fortaleza (RMF). Por fim, verifica-se a existência de investimentos em pequenos municípios do litoral do Ceará, tais como: Paracuru, Cruz e Jijoca de Jericoacara. Apenas o município de Itapajé, que possui investimentos de capital africano, não está localizado no litoral. 
Cartograma 5 - Estabelecimentos registrados por nacionalidade dos africanos na JUCEC por municípios do Ceará no período de 2000-2012

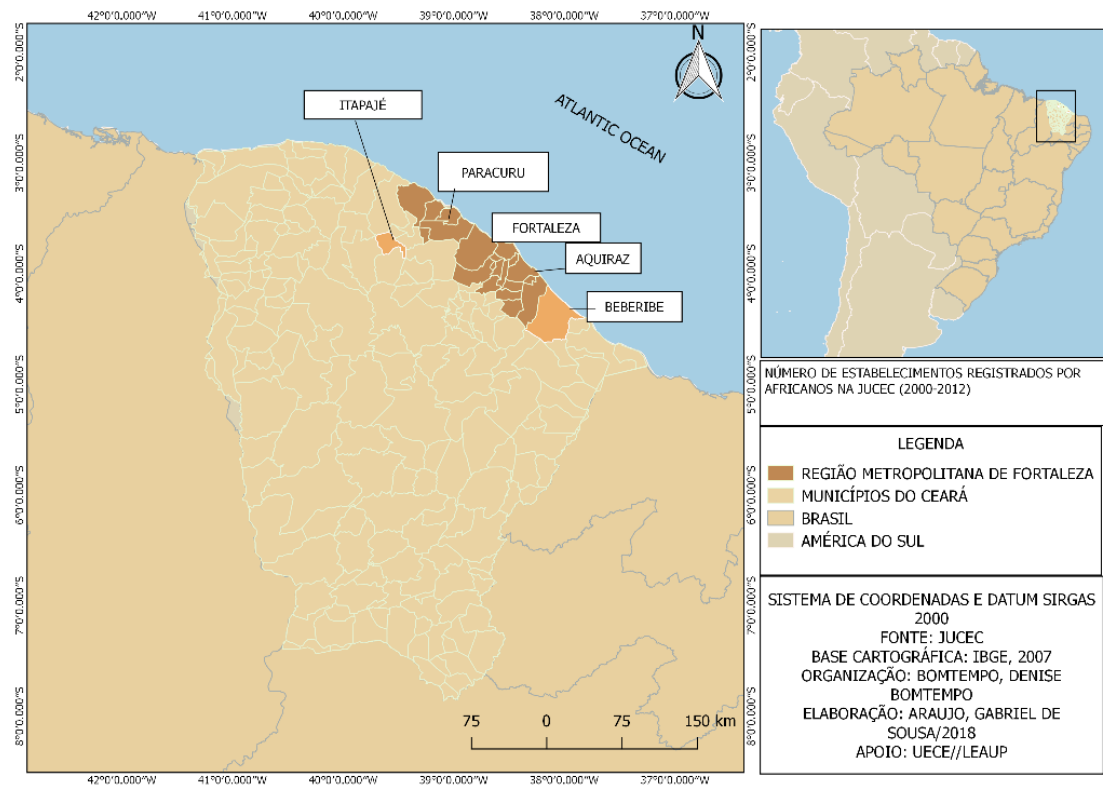

Fonte: JUCEC (2000-2012); Bomtempo; Sena (2018).

No período de 2000-2006 existiam no Ceará apenas 12 estabelecimentos de capital africano registrados, já em 2007-2012 ocorreu o aumento de mais nove estabelecimentos. No que se refere às atividades desempenhadas pelos proprietários dos estabelecimentos, destacam-se atividades vinculadas ao circuito superior da economia: comércio varejista de mercadorias em geral, com predominância de produtos alimentícios minimercados, mercearias e armazéns, além de restaurantes, lanchonetes, agências de viagem, serviço de hospedagem, dentre outros. De maneira geral, de acordo com a JUCEC (2012), do ponto de vista do volume de capital investido, pode-se classificar os estabelecimentos como pequenos e médios investimentos.

Ainda em relação aos investimentos africanos em território cearense, além daqueles de pequeno e médio porte, vale ressaltar que os últimos anos foram marcados pela presença de grandes investimentos (cerca de 300 milhões de reais) provenientes de uma única empresa de capital 
angolano materializado em território cearense. Trata-se das atividades desenvolvidas pela empresa Angola Cables - multinacional de Luanda, que tem como objetivo a instalação de cabos submarinos de fibra ótica que conecta os continentes por meio de sistemas de alta conexão para transmissão de dados informacionais ${ }^{3}$.

Diante de tais investimentos, a cidade de Fortaleza, por um lado, amplia o seu papel na divisão territorial do trabalho por intermédio de investimentos africanos, por outro, fomenta ainda mais a migração de investidores e profissionais qualificados para desenvolver atividades laborais articuladas a este grupo empresarial. Pode-se, portanto, afirmar que os africanos contribuem para que seja estruturada uma economia urbana da migração, já que dinamizam as atividades enquanto estudantes, investidores, proprietários e trabalhadores inseridos em diferentes atividades, ao mesmo tempo também participam enquanto consumidores do cotidiano das cidades nas quais estão inseridos pelas atividades laborais.

Economia urbana e territorialidade: os chineses nas cidades cearenses

A expansão das atividades comerciais atreladas à migração dos chineses articula de maneira mais intensa a metrópole Fortaleza, mas na escala temporal analisada, entrelaça também municípios da RMF (Guaiuba e Maracanaú), municípios que desempenham funções regionais, tais como: Juazeiro do Norte, Sobral, Crato, Iguatu e cidades locais, conforme aponta o Cartograma 6. Esses migrantes ocupam impreterivelmente os centros comerciais das cidades supracitadas. 
Cartograma 6 - Investimento chinês no Ceará (2000-2012)
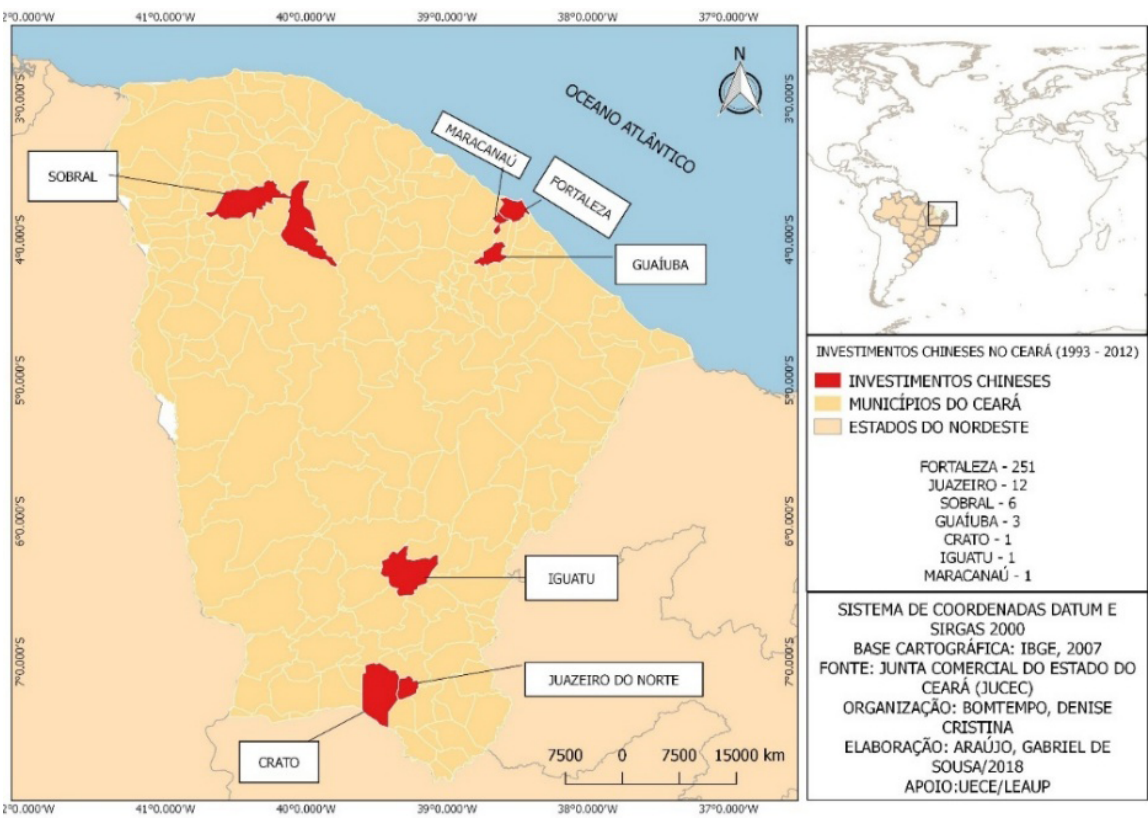

Fonte: JUCEC (2000-2012); Bomtempo; Araújo (2018).

Ao percorrer o centro das cidades, em especial, Fortaleza, é possível detectar a presença chinesa no comércio vinculado ao "circuito superior marginal" da economia, sobretudo em atividades de comando dos estabelecimentos. Todavia, em outras áreas da cidade (calçadão da Beira Mar - com forte concentração de turistas) foi possível verificar a inserção dos migrantes chineses em atividades laborais que se articulam ao circuito superior marginal e inferior da economia urbana.

De acordo com dados obtidos através da JUCEC (2012), os estabelecimentos registrados por migrantes chineses em Fortaleza estão localizados no centro da cidade, em galerias comerciais e também nas ruas em que o ritmo comercial é intenso, tais como: Floriano Peixoto, Major Facundo, Guilherme Rocha, Senador Pompeu, General Sampaio e Vinte Quatro de Maio. Ao se concentrar na área central das cidades cearenses, os chineses formam seus territórios de circulação de mercadorias e informações comerciais, bem como a manutenção de laços de amizade 
e parentesco. A presença da família chinesa em seus estabelecimentos é uma constante, desde o integrante mais novo, como crianças de colo, adolescentes, até o patriarca.

Em relação ao local de moradia (Cartograma 7), os migrantes chineses residentes em Fortaleza não habitam os bairros periféricos, como normalmente ocorre com os migrantes africanos (estudantes, trabalhadores com pouca qualificação), mas sim os bairros com boas condições infraestruturais, inseridos na Regional II de Fortaleza e reconhecidos por abrigar uma população com alto poder aquisitivo, e com inúmeros serviços modernos instalados. Os bairros são: Centro, Mucuripe, Praia de Iracema, Aldeota e Meireles. Todavia, nos últimos anos, presencia-se uma recente expansão da classe média residente em Fortaleza para os bairros mais distantes da área central e turística da cidade, tais como: Maraponga, Messejana, Cambeba e Parque Iracema. Enquanto escolha do local de moradia, os chineses também seguem essa direção.

Cartograma 7 - Residências de chineses que possuem estabelecimentos comerciais no centro de Fortaleza

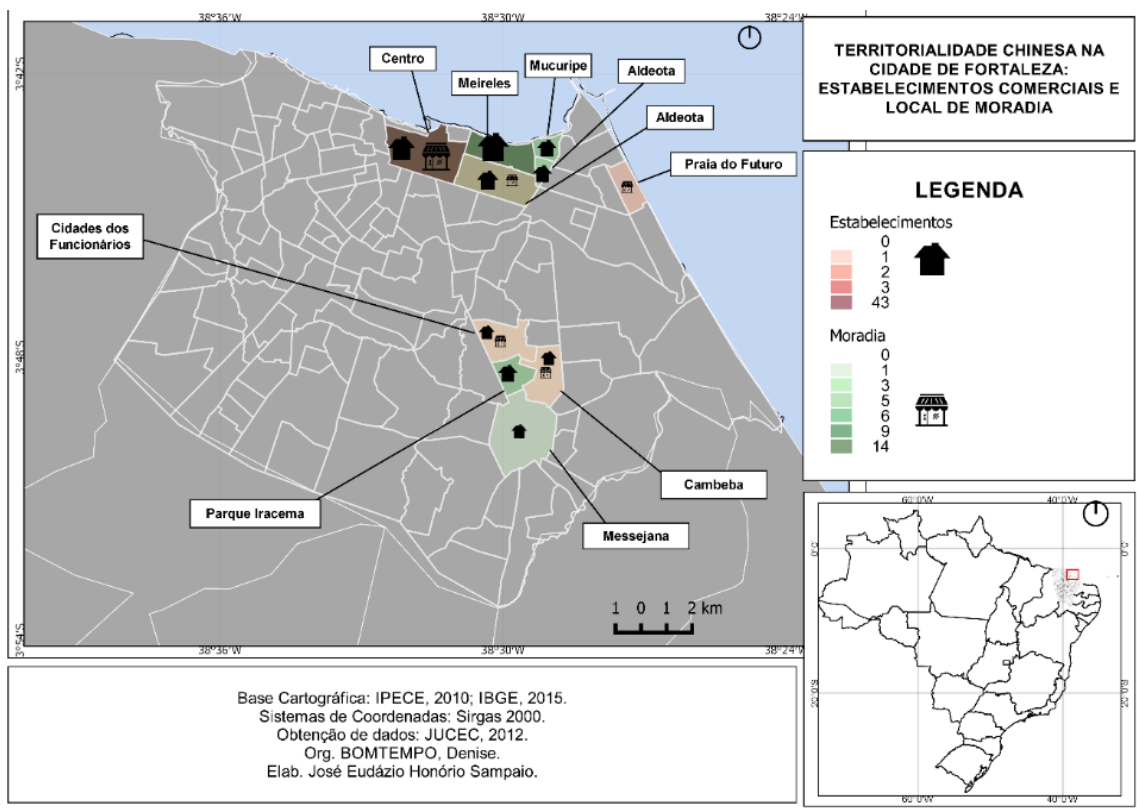

Fonte: JUCEC (2000-2012); Bomtempo; Sampaio (2018). 
Como já destacado, existe uma vinculação direta entre a migração chinesa no Ceará e o circuito superior e superior marginal da economia urbana. Entre as características que atribuímos ao circuito superior marginal, presente nos estabelecimentos comerciais dos migrantes chineses, destacam-se a estrutura organizacional do estabelecimento, a presença de funcionários, as formas de pagamento realizadas em espécie, cheques ou através de cartões de créditos de várias financeiras. Nos estabelecimentos, também são oferecidas notas fiscais, além das lojas estarem registradas no cadastro da JUCEC, portanto, são empresas que recolhem impostos.

Vale a pena mencionar que a presença dos migrantes chineses é evidenciada na organização de seus estabelecimentos, através da disposição dos produtos, do nome fantasia da empresa, dos artigos de decorações como a presença de símbolos vinculados à cultura oriental, tais como: leques e bonecas chinesas. O nome fantasia dos estabelecimentos também revela muito sobre a territorialidade desses migrantes no comercio fortalezense ao ressaltarem símbolos e nomes que reportam à sua cultura, tais como: China bolsas, Hong Kong Variedades, Lanchonete Dragão do Leste, Made in China Variedades, Taiwan importados, dentre outros.

Diante do apresentado, é possível afirmar que a inserção dos chineses na cidade de Fortaleza ocorreu como parte de um processo global de migração. Ao chegar no Ceará, a inserção se deu pela via do trabalho e investimentos no circuito superior marginal e inferior, contribuindo assim para a configuração de uma economia urbana da migração nas cidades de maior centralidade na rede urbana cearense, em especial Fortaleza. A territorialidade dos chineses pela via do trabalho e moradia, como foi possível constatar, fica restrita a uma parte da cidade de Fortaleza que apresenta maior infraestrutura urbana, desse modo, o migrante chinês cria territorialidades segmentadas e próprias.

\section{Economia urbana e territorialidade: os coreanos na RMF}

Em fins do século XX, mas sobretudo nas primeiras décadas do século XXI, a presença coreana no Brasil não está mais restrita à cidade de São Paulo, mas nota-se a presença coreana em outros estados brasileiros, entre eles o Ceará. 
A inserção do migrante coreano no Ceará está vinculada diretamente à consolidação das políticas de atração de investimentos do governo do Estado que, de acordo com Pereira Júnior (2011), gerou um movimento de atração, dispersão e relocalização de investimentos de grupos empresariais nacionais e internacionais. A materialização desses investimentos, ocasionou, entre outros, o fluxo de trabalhadores estrangeiros, entre eles, coreanos.

No Ceará, no que concerne à presença dos coreanos, é pertinente fazer uma periodização e considerar três momentos. No primeiro momento, essa migração ocorreu de maneira espontânea, ou seja, os migrantes chegaram para desenvolver atividades múltiplas, sobretudo vinculadas ao comércio. O segundo momento, consideramos que se tratou de uma migração direcionada, já que está atrelada à instalação de equipamentos industriais provenientes das políticas de investimentos. Esse segundo momento, data de 2010, quando da chegada da Companhia Siderúrgica do Pecém (CSP), empreendimento que possui como acionistas a empresa brasileira Vale S.A. e duas empresas coreanas, são elas: Dongkuk Steel e Posco. A construção da Unidade trouxe uma significativa mão de obra coreana que se instalou de forma perceptível no território cearense. O terceiro momento da migração coreana em território cearense (ainda em curso) só pode ser compreendido se considerarmos o início das operações da CSP, na qual garantiu a permanência de parte desses migrantes articulados diretamente à CSP e também daqueles que atualmente realizam atividades econômicas diversas e não atreladas à siderúrgica em apreço.

Ainda no que concerne à estruturação da CSP, a construção do empreendimento foi dividida em fases. Na primeira fase, foram realizadas atividades da construção civil, mobilizando significativa mão de obra, aproximadamente 3.900 empregados, tanto contratados pela empresa como terceirizados. Ao considerar a construção da siderúrgica com obras que tinham prazo para acabar, houve a contratação de trabalhadores temporários, por aproximadamente um ou dois anos.

De acordo com Teles (2014, p. 133), “[...] a mão de obra foi originária dos diversos estados brasileiros e da Coreia do Sul." Os trabalhadores coreanos, tendo uma melhor condição econômica, escolheram localidades turísticas, especialmente Caucaia (Vila do Cumbuco), São Gonçalo do Amarante, Pecém e Fortaleza para residir (Cartograma 8). 
Com a chegada da CSP, entre 2010 e 2014, aumentaram também os vínculos formais de trabalho dos coreanos no Ceará. Em 2010, segundo dados da RAIS/MTE, existia apenas um trabalhador coreano com vínculo formal; já em 2012, esse número subiu para 79; em 2014 já existiam 941 trabalhadores com vínculo formal de trabalho.

Cartograma 8 - Habitação de migrantes coreanos diretamente ligados à CSP

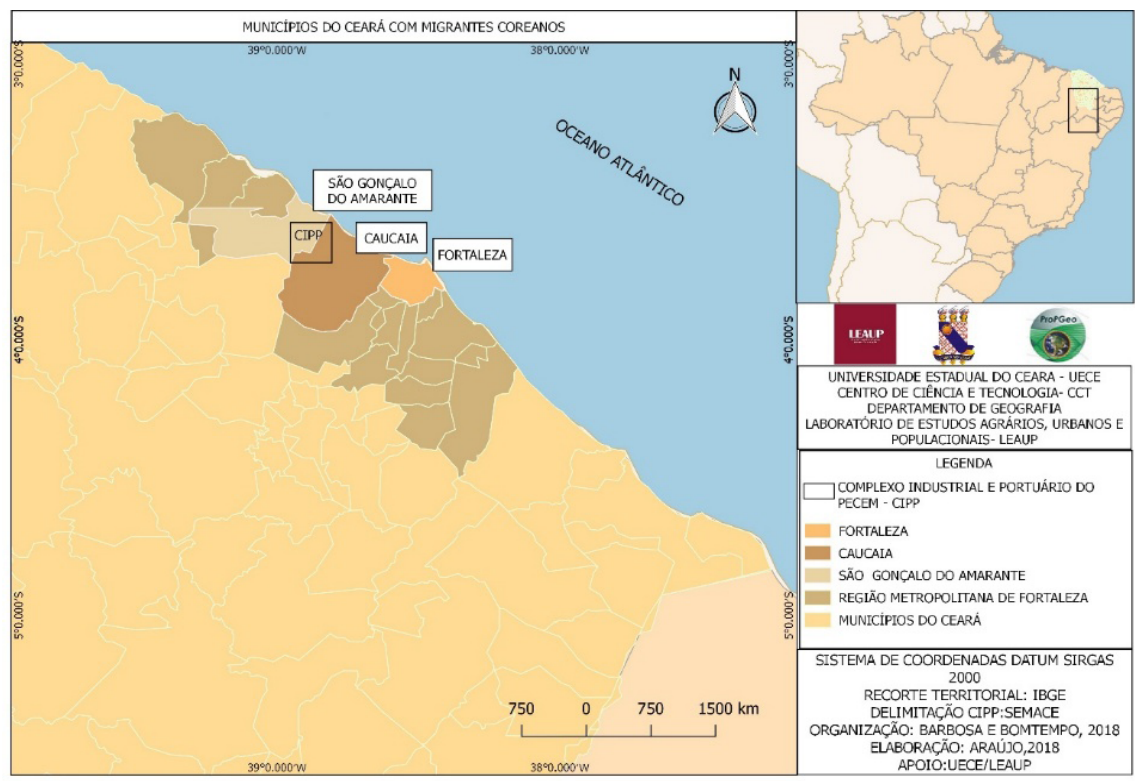

Fonte: Pesquisa Empírica (2018); Bomtempo; Barbosa (2018).

Além dos investidores diretos da CSP e dos trabalhadores ligados a esta empresa, destacam-se, de acordo com dados da JUCEC, no período de 2000 a 2012 a territorialização de investimentos comerciais diversos de sul-coreanos no Ceará, na qual articulava a escala metropolitana, sobretudo em Caucaia (Vila do Cumbuco) e São Gonçalo do Amarante, como também se fazia presente na metrópole Fortaleza. O primeiro investimento comercial coreano no Ceará foi realizado no ano de 2000 e instalado na cidade de Fortaleza (antes da chegada da CSP). Passaram-se cinco anos para que novos investimentos fossem realizados, assim, em 2005, foram totalizados quatro investimentos de capital coreano na 
cidade de Fortaleza e principalmente no setor de comércio. Nos anos de 2007 e 2008 tivemos a instalação de dois estabelecimentos (um em cada ano) comerciais na cidade de Fortaleza. O volume e o tipo, bem como a territorialização dos investimentos sofreram uma alteração no ano de 2012 em relação aos anos anteriores. Foi detectado a instalação de oito empresas de capital coreano, sendo duas em São Gonçalo do Amarante; três em Caucaia (Vila do Cumbuco) e três em Fortaleza. Essas empresas estavam vinculadas ao setor hoteleiro, prestação de serviços imobiliários, transporte de cargas, construção civil, restaurantes e confecções.

Como foi verificado a partir dos dados da JUCEC, em 2012 os estabelecimentos provenientes dos investimentos coreanos foram instalados, em sua maioria, nos municípios que fazem parte da RMF e estão próximos à CSP e CIPP, o que leva a afirmar que grande parte deles entraram em funcionamento para atender as demandas da própria CSP (já que as obras de instalação se iniciaram em 2012), como é o caso das empresas de Engenharia e Construção, como também da população migrante coreana, a exemplo das empresas de alimentação, hotéis e serviços em geral.

No Cartograma 9, observamos as territorialidades coreanas existentes no Ceará neste início do século XXI, no que concerne aos locais de trabalho (investimentos comerciais) e moradia. Na cidade de Fortaleza, os coreanos, assim como os chineses, residem nos bairros que possuem melhores infraestruturas urbanas e que abrigam uma população com maior renda e poder aquisitivo. São os bairros: Meireles, Aldeota, Centro, Papicu e Cidade dos Funcionários. Na sequência, os bairros como Vila União e Maraponga, passam por uma reestruturação, sobretudo pelo funcionamento de atividades modernas e novas formas de moradia (condomínios fechados horizontais e verticais). Nos bairros Mondumbim e Bom Jardim, nota-se a presença dos coreanos, mas em menor proporção que os demais bairros mencionados, já que possuem precariedades do ponto de vista da infraestrutura urbana e, portanto, não atrativos para moradia deste perfil de migrantes (investidores e com qualificação profissional).

Ainda no que concerne às territorialidades coreanas vinculadas ao local de moradia e investimentos, os municípios da RMF, São Gonçalo do Amarante e Caucaia, sobretudo a Vila do Cumbuco se destacam em relação à presença desses migrantes, como pode ser visualizado no Cartograma 9. 
Cartograma 9 - Territorialidade coreana na RMF: estabelecimentos comerciais e locais de moradia

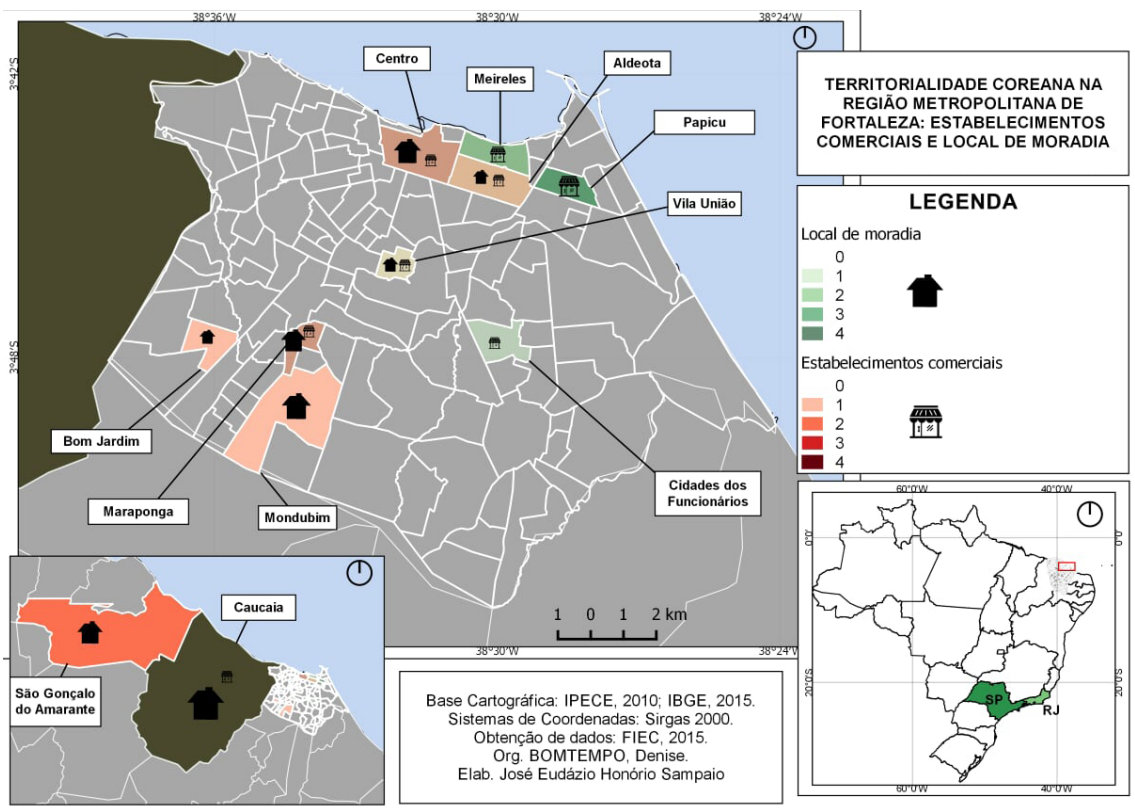

Fonte: Pesquisa Empírica (2018); Barbosa; Bomtempo; Sampaio (2018).

Dado o início das operações da CSP no CIPP (2017), a intensidade do fluxo migratório dos coreanos ganhou outros direcionamentos e conteúdos e por isso consideramos a emergência de um terceiro momento da migração coreana no Estado. Marcado, por um lado, pelo retorno e, por outro, pela permanência e ampliação das territorialidades coreanas, ou seja, o terceiro momento desta migração ainda está em curso. Entretanto, mesmo em curso, já podemos afirmar que este terceiro momento da migração coreana no Ceará é composto: a) pelo retorno de grande parte dos coreanos para o país de origem ${ }^{4}$, dada a finalização do contrato de trabalho com a CSP; b) pela permanência dos profissionais qualificados vinculados à CSP no Ceará; c) pela presença de profissionais autônomos que vieram para o Brasil a fim de trabalhar na CSP, mas que após finalizarem o contrato decidiram permanecer no Ceará e realizar investimentos em atividades vinculadas ao circuito superior da economia urbana; d) migrantes 
coreanos que vieram para o Ceará para desenvolver atividades econômicas sem ter vínculo com a CSP.

A territorialização do que consideramos o terceiro momento da migração coreana no Ceará ganha uma configuração territorial diferente dos momentos anteriores, já que grande parte dos migrantes instalados em território cearense, no primeiro e segundo momento da migração, residiam na região metropolitana (Vila do Cumbuco, Caucaia e São Gonçalo do Amarante). Neste terceiro momento, verificamos, a partir da pesquisa empírica, que o local de residência, de trabalho - investimentos, consumo e lazer deixou de ser realizado na região metropolitana, mas ganhou centralidade na metrópole Fortaleza.

Em Fortaleza, verifica-se uma diversificação das atividades empreendidas pelos coreanos pertencentes tanto ao grupo dos extrabalhadores da CSP, como também a migrantes que não possuíram, em nenhum momento, qualquer vínculo com a Empresa. Entre os estabelecimentos, a ênfase é dada para o comércio (confecção e restaurantes de comida coreana) e indústria de confecções.

Diante do exposto, a territorialidade dos migrantes coreanos se faz perceptível a partir das práticas espaciais evidenciadas na metrópole. Os investimentos coreanos estão dispersos em bairros com mais infraestruturas da cidade de Fortaleza (Meirelles, Aldeota e Papicu), diferentemente dos chineses que tem seus investimentos comerciais mais concentrados no centro da cidade. Ainda, em relação ao perfil dos migrantes coreanos, a mão de obra qualificada empregada na CSP demonstra que se trata de um perfil de migrante com qualificação profissional e com alto poder aquisitivo, na medida em que o conhecimento técnico voltado a indústria é de responsabilidade desses sujeitos. Além disso, as instalações de hotéis e restaurantes direcionados aos sul-coreanos determina uma territorialidade a partir do consumo, ao notar que os estabelecimentos não aparecem em grande quantidade, mas exercem um nó e possuem centralidade, quando se trata de aglomerar sujeitos que se aproximam pelos laços com o lugar de origem.

\section{Considerações finais}

Os fluxos migratórios internacionais no século XXI são direcionados principalmente para as grandes cidades, que cada vez mais, se tornam 
"lócus" de recepção dos sujeitos em mobilidade. Ao contrário do quadro histórico das migrações internacionais no Brasil, que enfatizou um fluxo para regiões como Sul e Sudeste, e cidades como São Paulo, novas regiões e centros urbanos no país recebem cada vez mais estrangeiros. É assim que o Ceará se insere no novo quadro do movimento da população no Brasil, entre outros aspectos, por receber importante contingente de migrantes de outros países.

Os fluxos migratórios que entrelaçam o Ceará no início do século XXI são internos (metrópole e cidades com diferentes papéis) e internacionais. Dos fluxos internacionais, predominam: migrantes com baixa ou sem qualificação profissional e qualificados (investidores) e estudantes.

Dos investidores, caracterizam-se: a) grandes investimentos: indústria; agronegócio; compra de terras; incorporação; construção civil; imobiliária; hotelaria; importação e exportação; e b) Pequenos e médios investimentos: comércio e serviços.

Os investimentos são feitos sobretudo em Fortaleza e RMF, em municípios do litoral e do "interior" do estado, com papéis de centralidade na rede urbana cearense. Os investidores com a permissividade dos agentes internos "normatizam, "usam" o território, produzem territorialidades próprias e configuram a economia urbana da migração.

Nas cidades cearenses existem territorialidades múltiplas que se materializam na paisagem de acordo com cada perfil econômico e cultural dos migrantes, sobretudo internacional.

Desse modo, as recentes migrações que hoje entrelaçam o Ceará, permitem entender, o "novo" papel desempenhado pelo Estado na divisão territorial do trabalho, a partir do surgimento de uma economia urbana da migração, bem como novas territorialidades que são materializadas na escala das cidades que concentram população.

As territorialidades produzidas demonstram as desigualdades do ponto de vista das práticas cotidianas vinculadas à moradia, ao trabalho, ao consumo e ao lazer, como ficou evidenciado entre os migrantes africanos, chineses e coreanos descritos neste trabalho. 


\section{Notas}

1 SANTOS, M. O espaço dividido: os dois circuitos da economia urbana em países subdesenvolvidos. São Paulo: Edusp, 2014.

2 Para mais informações sobre o Programa de Estudantes-Convênio de Graduação, por favor, acessar <http://portal.mec.gov.br/pec-g $>$.

3 Fonte: Hemeroteca desenvolvida no LEAUP. Disponível em: <https://www.opovo.com. $\mathrm{br} /$ noticias/economia/2017/04/angola-cables-investira-us-50-milhoes-em-fortalezaeste-ano.html>. Acesso em: 18 jan. 2018).

4 De acordo com Sayad (1998), o retorno é algo muito esperado no movimento migratório, muitas vezes o migrante só aceita a migração pela possibilidade do retorno.

\section{Referências}

AUGÉ, M. Por uma antropologia da mobilidade. Tradução Bruno César Cavalcanti e Rachel Rocha de Almeida Barros. Lameiras, Maceió: EDUFAL/UNESP, 2010.

BAENINGER, R. Migrações internas no Brasil século 21: evidências empíricas e desafios conceituais. In: CUNHA, J. M. P. da. Mobilidade espacial da população: desafios teóricos e metodológicos para o seu estudo. Campinas: Núcleo de Estudos de População-Nepo; Unicamp, 2011. 184p.

BOMTEMPO, D. C. Os sonhos da migração: um estudo dos japoneses e seus descendentes no município de Álvares Machado - SP. 2003. Dissertação (Mestrado em Geografia) - Faculdade de Ciências e Tecnologia, Universidade Estadual Paulista Presidente Prudente, 2003.

BOMTEMPO, D. C.; SPOSITO, E. S. Entre o Japão e o Brasil: a territorialidade dos migrantes isseis e dekasseguis. In: SAQUET, M. A.; SPOSITO, E. S. (Org.). Territórios e territorialidades: teorias, processos e conflitos. 1.ed. São Paulo: Expressão Popular, 2009. p. 229-248. (v. 1).

BOMTEMPO, D. C.; SENA, K. B. P. Migração Internacional e territorialidades: os africanos no Ceará. In: ENCONTRO NACIONAL DA ASSOCIAÇÃO BRASILEIRA DE ESTUDOS POPULACIONAIS, 21, 2018, Poços de Caldas. Anais do XXI Encontro Nacional de Estudos Populacionais: Poços de Caldas, Minas Gerais, 2018. Disponível em: < https://www.adtevento.com.br/2018/abep/ sis/inscricao/resumos/0001/R0241-1.PDF >. Acesso em: 19/11/2018.

FERREIRA, E. S. Migração internacional e economia urbana: os chineses no território cearense. 2016. 198 f. Dissertação (Mestrado em Geografia) - Centro de Ciência e Tecnologia, Universidade Estadual do Ceará, 2016.

FERREIRA, E. S.; BOMTEMPO, D. C. A China que ninguém vê: migrantes chineses no centro comercial das cidades cearenses. Boletim de Geografia de Maringá, Maringá, v. 36, n. 1, p. 48-61, 2018.

GAUDEMAR, J. P. de. Mobilidade do trabalho e acumulação do capital. Lisboa: Estampa, 1977. 
GOETTERT, J. D. Paradoxos do lugar mundo: brasileiro e identidades. In: SPOSITO, E. S.; BOMTEMPO, D. C.; SOUSA, A. A. (Org.). Geografia e migração: movimentos, territórios e territorialidades. São Paulo: Expressão Popular, 2010.

HAESBAERT, R. O mito da desterritorialização: do "fim dos territórios" à multiterritorialidade. Rio de Janeiro: Bertrand Brasil, 2004.

LANGA, E. N. B. Diáspora Africana no Ceará no Século XXI: ressignificações identitárias de estudantes imigrantes. Tese (Doutorado) - Centro de Humanidades, Universidade Federal do Ceará, Fortaleza, 2016.

. Noites Africanas em Fortaleza, Liminaridade e Ressignificações İdentitárias. In: COLÓQUIO INTERNACIONAL DIÁLOGOS JUVENIS: DIMINUINDO DISTÂNCIAS ENTRE NARRADORES E PESQUISADORES, 1, 2012, Fortaleza. Anais... Fortaleza: EDUFC, 2012. p. 106-106.

LÉVY, J.; LUSSAULT, M. Dicionnaire de la Géographie et l'espace des sociétes. Belin: Paris, 2003.

MARANDOLA, J. E.; DAL GALLO, P. M. Ser migrante: implicações territoriais e existenciais da migração. Revista Brasileira de Estudos Populacionais, Rio de Janeiro, v. 27, n. 2, p. 407-424, jul./dez. 2010.

MTE. Ministério do Trabalho e Emprego. Disponível em: <www.mte.gov,br>. Acesso em: 15 set. 2019.RAFFESTIN, C. Por uma Geografia do Poder. São Paulo: Ática, 1993.

SANTOS, M. O espaço dividido: os dois circuitos da economia urbana. 2. Ed. São Paulo: EDUSP, 2004.

SAYAD, A. A imigração e os paradoxos da alteridade. São Paulo: Edusp, 1998. . La double absence: Des illusions de l'émigre aux soufrances de l’immigre. Paris: Éditions du Seuil, 1999.

SORRE, M. Geografia. São Paulo: Editora Ática, 1984.

TELES, G. A. Mobilidade da força de trabalho e produção do espaço: o complexo industrial e portuário do Pecém na região metropolitana de Fortaleza. Revista Pegada, v. 15 n. 2, 2014. Disponível em: < http://revista.fct.unesp.br/index.php/ pegada/article/viewFile/2951/2812>. Acesso em: 20 jul. 2016.

Denise Cristina Bomtempo - Licenciada em Geografia pela UNESP/P . Prudente. Mestre e Doutora em Geografia pelo Programa de Pós-Graduação em Geografia UNESP/P. Prudente. Atualmente é Professora Adjunta dos cursos de Graduação em Geografia e do Programa de Pós-Graduação em Geografia da Universidade Estadual do Ceará, Coordenadora e Pesquisadora do Laboratório de Estudos Agrários, Urbanos e Populacionais . (D) https://orcid.org/0000-0002-0720-2110

Recebido para publicação em 20 de janeiro de 2019 Aceito para publicação em 25 de fevereiro de 2019 Publicado em 4 de abril de 2019 